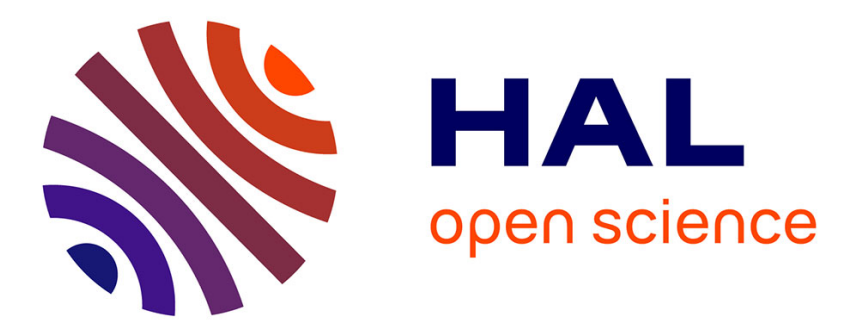

\title{
Use of supercritical fluid extraction as a method of cleaning anterior cruciate ligament prostheses - In vitro and in vivo validation
}

Jacques Fages, N Poddevin, M W King, Y Marois, J Bronner, B Jakubiec, R Roy, D Mainard, G Laroche, Jean-Pierre Delagoutte, et al.

\section{To cite this version:}

Jacques Fages, N Poddevin, M W King, Y Marois, J Bronner, et al.. Use of supercritical fluid extraction as a method of cleaning anterior cruciate ligament prostheses - In vitro and in vivo validation. ASAIO Journal, 1998, 44 (4), pp.278-288. hal-01697289

\section{HAL Id: hal-01697289 \\ https://hal.science/hal-01697289}

Submitted on 21 Mar 2018

HAL is a multi-disciplinary open access archive for the deposit and dissemination of scientific research documents, whether they are published or not. The documents may come from teaching and research institutions in France or abroad, or from public or private research centers.
L'archive ouverte pluridisciplinaire HAL, est destinée au dépôt et à la diffusion de documents scientifiques de niveau recherche, publiés ou non, émanant des établissements d'enseignement et de recherche français ou étrangers, des laboratoires publics ou privés. 


\title{
Use of Supercritical Fluid Extraction as a Method of Cleaning Anterior Cruciate Ligament Prostheses
}

\author{
In Vitro and In Vivo Validation \\ Jacques fages, *\| Nicolas Poddevin,* Martin W. King, †¥ Yves Marois, + Joseph Bronner, $\boldsymbol{\emptyset}$ \\ Barbara Jakubiec, $\$$ Raynald Roy, $§$ Didier Mainard, $\|$ Gaetan Laroche, $†$ \\ Jean-Pierre Delagoutte, $\mid$ and Robert Guidoint
}

The process of supercritical fluid extraction (SFE) using carbon dioxide as the mobile phase is finding increasing numbers of applications in a wide variety of industries for the extraction, separation, and cleaning of materials. This study assessed the usefulness of this approach in removing surface contaminants from a knitted polyester anterior cruciate ligament (ACL) prosthesis before packaging and sterilizing the product during manufacture. The physical, dimensional, and chemical properties of SFE treated compared with commercially scoured control samples were characterized using a number of textile test methods: electron spectroscopy for chemical analysis, Fourier transform infrared spectroscopy, differential scanning calorimetry, and solvent extraction analysis. The biocompatibility of the samples was measured in terms of their ability to generate CD18 integrin expression on activated human polymorphonuclear cells, and their inflammatory response when implanted for up to $\mathbf{3 0}$ days in the knee joint of rats. SFE treatment was successful in removing most of the nonpolar contaminants from the $\mathrm{ACL}$ prosthesis and reducing the amount of residuals to a commercially acceptable level. However, some nitrogen containing compounds and polar salts were not removed by the SFE process. The results from the biocompatibility tests demonstrated that the cleaner SFE treated prosthesis induced significantly lower CD18 expression than the scoured control fabric, and was also associated with a milder inflammatory response and a more rapid rate of healing during the $\mathbf{3 0}$ day animal trial. Another effect of SFE processing was to cause the polyester device to shrink and lose porosity because of yarn contraction and modification of the polymer's microcrystalline structure. ASAIO Journal 1998; 44:278-288.

From *Bioland Biomatériaux, Toulouse, France, the tDepartment of Surgery, Laval University and Institut des Biomatériaux du Québec, $\mathrm{CH \cup Q}$, Quebec City, the fDepartment of Clothing and Textiles, University of Manitoba, Winnipeg, Manitoba, the §Unité de Recherche, Inflammation, Immunologie et Rhumatologie, CHUQ, Quebec City, Quebec, Canada, and the $\$$ Service d'Orthopédie et de Traumatologie, $\mathrm{CHU}$ and Institut Européen de Biomatériaux et de Microchirurgie, Nancy, France.

|Current address: Ecole Nationale Supérieure des Techniques Industrielles et des Mines d'Albi-Carmaux, Albi, France.

Submitted for consideration June 1997; accepted for publication in revised form February 1998.

Reprint requests: Dr. Robert Guidoin, Laboratoire de Chirurgie Expérimentale, Local 1701, Pavillon de Services, Université Laval, Québec, Québec, G1K 7P4 Canada.
When any prosthetic device is implanted in the body, the chemical nature of the polymer and the structure of the prosthesis are two important features that influence its in vivo stability and resistance to biodegradation. An ideal prosthesis should provide adequate biocompatibility and biofunctionality and provoke only a mild tissue reaction, thus ensuring longterm biostability and durability. Another factor that influences the fate of a synthetic prosthesis is the cleanliness of its surface after manufacture, packaging, and sterilization. Clean surfaces are essential for vascular grafts, ligament prostheses, and hernia patches to preclude any adverse reaction and provide a satisfactory healing response. ' Surface contaminants have been shown to have a detrimental effect on the performance of vascular grafts. Studies have demonstrated that unclean prosthetic surfaces generate cytotoxic effects, compromising the migration, adhesion, and viability of cells in vitro. ${ }^{2}$ These contaminants are chemical compounds, often oils or lubricants, that have been purposely applied to facilitate the processing of the textile yarns during manufacture. Other chemicals, such as polyvinyl alcohol and starch, are sometimes used to protect the yarns from abrasion during weaving. ${ }^{3}$ Most of these chemicals are usually removed by detergents during a washing or scouring operation before sterilization. However, a small but significant residue often remains, and because of this, alternative cleaning procedures are needed..$^{4,5}$

The use of supercritical fluid extraction (SFE) has recently received much attention in the fields of agricultural, biologic, and environmental science for the extraction of specific chemicals from soils, tissues, and food products. ${ }^{6}$ Although this technique of converting a pure compound into a supercritical fluid by increasing the temperature and pressure conditions above certain critical values was first reported to the Royal Society of London in $1879,^{7}$ its use as an extraction, separation, and cleaning technology has emerged only in the last 20 years. ${ }^{6,8-10}$ In addition to finding applications in the food, cosmetic, and pharmaceutical industries, SFE has recently been shown to be an effective technique in the plastics industry for the extraction of oligomers from polymers, ${ }^{11}$ and in the biomedical industry for the extraction of additives from polymers ${ }^{12}$ and lipids from bone. $^{13,14}$ The literature also contains a number of references describing the effect of temperature and pressure on the sorption and transport of carbon dioxide in polyethylene terephthalate (PET; polyester) films. ${ }^{15,16}$ Whether the technique can be applied to other routine procedures, such as the cleaning 
of polyester implantable devices before packaging and sterilization, is a question that this study intended to address.

In fact, the current study was undertaken to determine the efficacy of SFE treatment for the cleaning of a polyester biotextile used as an anterior cruciate ligament (ACL) prosthesis. In addition to determining the cleanliness of the implant by chemical analysis before and after SFE processing, the effect of the treatment on the biocompatibility of the specimens was assessed using an in vitro cell activation study, as well as by implanting small samples of the device in the knee joint of rats for periods of up to 30 days.

\section{Materials and Methods}

\section{Selection of Materials}

The ACL prosthesis evaluated in this study was constructed from a two-bar, warp-knitted fabric composed of flat and texturized multifilament PET yarns. Two versions of this polyester prototype device were available for investigation. One had been given the SFE cleaning treatment, whereas the other, the control, had received only a regular scour.

\section{Supercritical Fluid Extraction Processing Conditions}

A pilot scale extractor SFE 3000 (Separex, Champigneulles, France) was used for the extraction and separation of nine $\mathrm{ACL}$ prosthesis samples in a batch process. Carbon dioxide at ambient temperature was liquefied by cooling, pressurized by a membrane pump (Lewa, Sartrouville, France), and then heated to the extraction temperature. The operating conditions in the $4 \mathrm{~L}$ extraction vessel were a temperature of $35^{\circ} \mathrm{C}$, a pressure of 280 bars, and an average $\mathrm{CO}_{2}$ flow rate of 44.6 $\mathrm{kg} / \mathrm{hr}$, which were maintained for an extraction time of 18 hours and 50 minutes. The flow of $\mathrm{CO}_{2}$ was measured by a Rosemount Micromotion D12 mass flowmeter that was part of the automated microcomputer control system. After extraction, the $\mathrm{CO}_{2}$ passed into two parallel, thermostatically controlled separation vessels where the pressure was adjusted by an analog valve. At the outflow of the separators, the $\mathrm{CO}_{2}$ was liquefied and recycled. The purity of the $\mathrm{CO}_{2}$ used was $99.7 \%$. These extraction conditions were selected to optimize the diffusivity of supercritical $\mathrm{CO}_{2}$ within the polyester semicrystalline polymer without exposing it to temperatures above its glass transition temperature. ${ }^{15,16}$ It was already known that the extractor could operate reliably and accurately under these conditions, which were similar to those used for the extraction of lipids from bovine bone. ${ }^{13}$

\section{Regular Scouring Conditions}

The scouring method used to clean the control samples was the well established, validated commercial process that is used by medical device manufacturers for the cleaning and finishing of polyester textile implants. ${ }^{3}$ It involves exposing the goods to an aqueous cleaning system in an ultrasonic bath using sterile, deionized, and filtered water and a nonionic detergent. After copious rinses in more sterile, deionized, and filtered water, the samples are transferred under clean room conditions to a drying oven with a supply of warm filtered air before inspection and packaging.

\section{Methods for Physical Characterization}

Surface Morphology. Scanning electron microscopy was used to observe the surface morphology and the presence of visible contaminants adhering to the surfaces of the SFE cleaned and control fabrics. Small specimens $\left(1 \mathrm{~cm}^{2}\right)$ were mounted on stubs and exposed to osmium tetroxide vapors, then coated with gold-palladium to improve their conduction. They were examined in a Jeol JSM-35CF scanning electron microscope (Soquelec, Montreal, Quebec, Canada) at an accelerating voltage of $15 \mathrm{kV}$. Photomicrographs were taken of the face and back of the fabrics as well as of cross-sections cut radially through the length of the ACL prostheses.

\section{Physical Properties and Textile Structure of Anterior Cruciate Ligament Prostheses}

Thickness. The ACL devices had a tubular form with an elliptical cross-section. Both major and minor axes ( $2 R$ and $2 r$, respectively) were measured using a Frazier Compressometer (Frazier Precision Instrument Co., Gaithersburg, MD) fitted with a $25.4 \mathrm{~mm}$ diameter presser foot at an applied pressure of $35 \mathrm{~g} / \mathrm{cm}^{2}$ (0.5 psi). The cross-sectional area of the ellipse, $A$, was then calculated using the equation:

$$
\mathrm{A}=\pi \mathrm{Rr}
$$

The thickness of the knitted fabrics, $h$, was also measured on a Frazier Compressometer using the same test conditions. ${ }^{17}$

Mass per Unit Length. A known length of each ACL prosthesis was conditioned in a standard atmosphere (temperature $21^{\circ} \mathrm{C} \pm 1{ }^{\circ} \mathrm{C}$, relative humidity $65 \% \pm 2 \%$ ) for at least 24 hours, measured, and weighed on a Sartorius digital analytic balance (Model 2400; Fisher Scientific, Edmonton, Alberta, Canada) to a precision of $0.1 \mathrm{mg}$. By dividing the mass by the length, the mass per unit length, $m$, was calculated in grams per meter and in tex (the weight in grams of a $1 \mathrm{~km}$ length). ${ }^{18}$

Mass per Unit Area. A known area of each knitted fabric was conditioned in a standard atmosphere for at least 24 hours, measured, and weighed on a Sartorius digital analytic balance to a precision of $0.1 \mathrm{mg}$. By dividing the mass of each specimen by its area, the mass per unit area, $M$, was calculated in grams per meter squared.

Porosity. The porosity is a measure of the percentage of the total volume of a structure that is occupied by pores or void spaces. It is calculated by dividing the density of the structure by the density of the polyester fibers of which it is composed, and subtracting this value from one.

The porosity of each ACL prosthesis was calculated using the following equation:

$$
P=100[1-m / \pi \operatorname{Rr} p]
$$

where $P$ is the percentage porosity, $m$ is the mass per unit length in grams per meter, $\mathrm{R}$ and $\mathrm{r}$ represent half the major and minor axes, respectively, of the elliptical cross-section in millimeters, and $p$ is the density of the PET fibers $\left(1.38 \mathrm{~g} / \mathrm{cm}^{3}\right)$.

The porosity of each knitted fabric was calculated using the following equation:

$$
P=100[1-M / 1000 h p]
$$

where $P$ is the percentage porosity, $M$ is the mass per unit area in grams per square meter, $h$ is the fabric thickness in 
millimeters, and $p$ is the density of the PET fibers $(1.38$ $\left.\mathrm{g} / \mathrm{cm}^{3}\right) \cdot{ }^{19,20}$

Fabric Stitch Density. A Wild Model M3B stereoscopic macroscope (Leica, Mississauga Ontario, Canada) was used at $\times 20$ magnification and dark field to count the wales per centimeter width and the courses and inserted picks per centimeter length. Each fabric was mounted in a relaxed state between two glass slides. The stitch density was calculated by multiplying the frequency of the columns of stitches (wales/centimeter) by the frequency of the rows of stitches (courses/centimeter). ${ }^{21}$

Yarn Filament Count. The number of filaments in the two types of yarns present in the fabrics was counted while viewing specimens mounted on a Wild Model M3B stereoscopic macroscope using dark field and $\times 20$ magnification. Five yarn specimens were selected at random from each type. The mode value of the five measurements was taken as the yarn filament count, $n$.

Filament Diameter. The diameters $(d)$ of the filaments in the two types of yarns present in the fabrics were measured in microns with an Olympus compound optical microscope (Model E; W. Carsen, Don Mills, Ontario, Canada) fitted with a Filar Olympus calibrated eyepiece micrometer. Twenty filaments were selected at random from each yarn and viewed at a magnification of $\times 400$.

Nominal Yarn Linear Density. The linear density of a yarn measures its coarseness in units of tex (i.e., mass in grams of a $1 \mathrm{~km}$ length) or of decitex (dtex; i.e., mass in grams of a 10 $\mathrm{km}$ length). The value $D$ is obtained experimentally either by weighing a precisely known length of yarn or by using the following equation to calculate it from other yarn dimensions.

$$
\mathrm{D}(\mathrm{dtex})=\frac{\pi \mathrm{np}}{100}(\mathrm{~d} / 2)^{2}
$$

where $n$ is the yarn filament count, $p$ is the density of the PET filaments $\left(1.38 \mathrm{~g} / \mathrm{cm}^{3}\right)$, and $d$ is the filament diameter measured in microns. ${ }^{3,22}$

\section{Methods for Chemical Characterization}

Electron Spectroscopy for Chemical Analysis. The spectra of the external surface of each device were obtained on a Lab MK2 electron spectroscopy for chemical analysis (ESCA) instrument (VG Scientific, East Grinstead, West Sussex, United Kingdom) using a magnesium-potassium- $\alpha$ beam. Survey scans were taken that gave the level of contaminants on the surfaces of the devices. ${ }^{23}$

Fourier Transform Infrared Spectroscopy. Infrared spectra were recorded with a Nicolet Magna-550 (Nicolet Instruments Corp., Madison, WI) Fourier transform infrared spectrometer fitted with a denterated triglycine sulfate detector and a germanium coated potassium bromide beamsplitter. An attenuated total reflectance mode was used to measure the infrared spectra near the surface of the two types of filaments found in the two fabrics. This involved a split pea attachment (Harrick Scientific Corp., Ossining, NY) equipped with a silicon hemispheric, $3 \mathrm{~mm}$ diameter, internal reflectance element that was bevelled around the edge to provide a sampling area slightly larger than the 150-200 $\mu$ m diameter hot-spot on the crystal. One hundred scans were aggregated with an optical retardation of $0.25 \mathrm{~cm}$, triangularly apodized, and Fourier transformed to yield a $2 \mathrm{~cm}^{-1}$ resolution. ${ }^{24}$
Differential Scanning Calorimetry. Specimens weighing between 5-10 mg were cut from each of the two types of filament yarns found within the two devices, placed in an aluminum pan, sealed, and heated from 220 to $280^{\circ} \mathrm{C}$ in a nitrogen atmosphere at a programed heating rate of $10^{\circ} \mathrm{C} / \mathrm{min}$ in a differential scanning calorimetry 7 thermal analyzer (Perkin-Elmer Canada, Ltd., Montreal, Quebec, Canada). The system was calibrated with a known weight of indium. The average melting temperature $(\mathrm{Tm})$, pre-melt temperature $(\mathrm{Tpm})$, heat of fusion $(\Delta H)$ and crystallinity index were determined from five specimens taken from each yarn sample. ${ }^{25}$ To calculate the crystallinity index, it was assumed that the heat of fusion for perfectly crystalline PET is $140 \mathrm{~J} / \mathrm{g} \cdot{ }^{26}$

Level of Extractables. The level of extractable material remaining on the surfaces of the two devices was determined by subjecting approximately $5 \mathrm{~g}$ samples to a series of multiple quantitative extractions using different solvents cycling in a Soxhlet extraction apparatus. The sequence of five solvents in increasing order of polarity was hexane, 1,1,1-trichloroethane, methanol, water, and $0.1 \mathrm{~N}$ hydrochloric acid. Gravimetric determination of the mass of each extract was performed by evaporating to dryness each solvent in turn, and expressing the level of extractable material as a percentage of the mass of the original sample. ${ }^{27}$

\section{Methods for Biologic Characterization}

In Vitro Cell Activation Study. Heparinized human blood was collected from four healthy adult volunteers. The red blood cells were allowed to separate out by gravity when placed in a Hank's solution containing 6\% Dextran for a period of 30 minutes at room temperature. The cells were then collected and centrifuged at $450 \mathrm{~g}$ for 15 minutes. After washing, they were separated by gradient centrifugation at $600 \mathrm{~g}$ for 20 minutes in Ficoll-Hypaque solution (Pharmacia, Uppsala, Sweden). The polymorphonuclear cell (PMN) population was collected and the residual red blood cells removed by hypotonic lysis. After washing, the PMN suspension was again centrifuged at $200 \mathrm{~g}$ for 15 minutes. After performing cell counts and viability determinations, a series of cell suspensions was prepared in Hank's $\left(\mathrm{Ca}^{2+}\right.$ and $\left.\mathrm{Mg}^{2+}\right)$ at a concentration of 1 $\times 10^{6}$ cell $\mathrm{s} / \mathrm{ml}$ for the in vitro activation study.

Both SFE and control polyester fabrics were cut and shaped into $16 \mathrm{~mm}$ diameter discs designed to fit the wells of a 24 well polystyrene cell culture plate (Nunclon Delta, Kamstrup, Denmark). To prevent the textile discs from floating, a $16 \mathrm{~mm}$ diameter Tygon O-ring (Fisher, Montreal, Quebec, Canada) was inserted over the material in each well. These procedures were performed under clean room conditions. The plates were sterilized with ethylene oxide for 3.5 hours at $63^{\circ} \mathrm{C}$, followed by a 24 hour aeration period at $55^{\circ} \mathrm{C}$. A series of four control experiments was also performed, which included the incubation of PMNs in the presence of a Tygon O-ring alone and in the presence of two primary reference materials (i.e., low density polyethylene [LDPE] and polydimethylsiloxane [PDMS]; National Heart, Lung, and Blood Institute, Bethesda, MD), as negative controls. As a positive control, the PMNs were also incubated in the presence of tumor necrosis factor.

Two milliliters of the PMN suspension was incubated with the different materials at $37^{\circ} \mathrm{C}$ in a $5 \% \mathrm{CO}_{2}$ atmosphere for 60 minutes. After incubation, the reaction was stopped by placing 

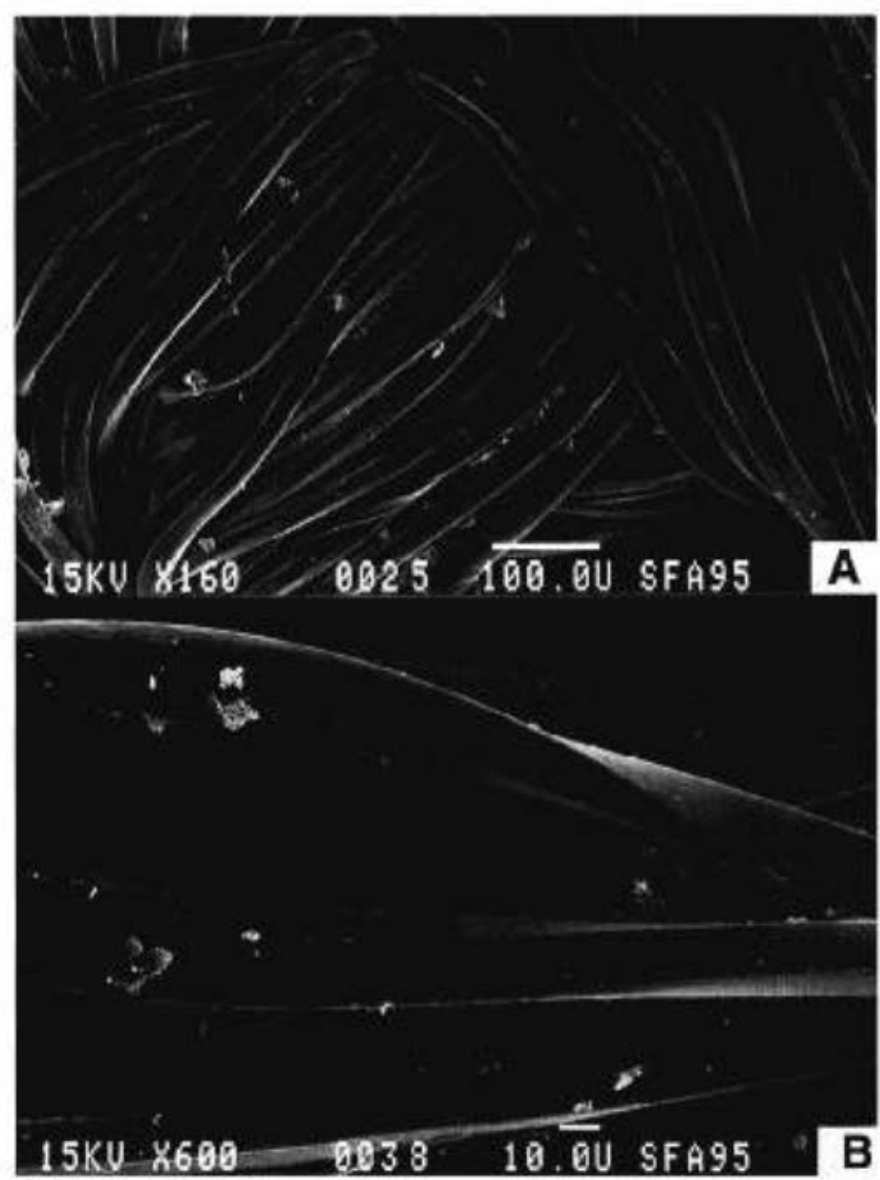

Figure 1. Scanning electron photomicrographs of the face of the control knitted fabric showing the presence of contaminants adhering to the surface of the polyester filaments (original magnifications, A: $\times 160$, B: $\times 600$ ).

the cell culture plates on ice. The cells were harvested and transferred to test tubes. They were then incubated with a murine monoclonal anti-human CD18 specific monoclonal antibody (anti-LFA01B subunit; ATCC, Rockville, MD) for 20 minutes at $4^{\circ} \mathrm{C}$. They were washed and incubated with a goat anti-mouse fluorescein isothiocyanate labeled antibody for 15 minutes at $4^{\circ} \mathrm{C}$, and, finally, the cells were washed, fixed in formaldehyde, and quantified with an Epics $C$ flow cytometer (Coulter Electronics Inc., Miami, FL) at $488 \mathrm{~nm} .^{28}$

In Vivo Implantation Study. Preparation of Specimens. The yarn specimens for implantation were prepared from both the SFE and control fabric by cutting and unrolling the tubular structure to remove individual weft insertion yarns measuring approximately $12 \mathrm{~mm}$ in length from the central region. Each yarn weighed approximately $2.5 \mathrm{mg}$. To avoid raveling and separation of the filaments, and to facilitate handling and insertion of the yarn in the knee joint of the rat, the specimens were knotted at both ends. They were then sterilized by ethylene oxide.

Surgery. Fifteen male Wistar rats weighing 300-400 g were anesthetized with $20 \mathrm{mg} / \mathrm{ml}$ ketamine and $2.5 \mathrm{mg} / \mathrm{ml}$ xylazine. Both hind legs were shaved and the skin disinfected with povidone-iodine. Under a sterile environment, an anteromedial arthrotomy was performed on each knee and one yarn specimen was inserted into each open knee joint. ${ }^{29}$ Specimens from the SFE and control fabrics were inserted respectively in the right and left knee of the same rat. A 7-0 monofilament polypropylene suture (Prolene; Ethicon Sutures, Ltd., Peterborough, Ontario, Canada) was used to close the joint capsule and the skin was closed with a 3-0 monofilament polypropylene suture. The animals were then returned to their cages, fed an unrestricted diet, and cared for according to the Canadian Guidelines on Animal Care Regulations. The animals were divided into three groups of five rats, each prescheduled for a period of implantation of 3, 10, or 30 days.

Graft Harvesting and Histopathologic Analysis. After the prescheduled implantation time, the animals were sacrificed by injection of an intraperitoneal overdose of sodium pentobarbital. The skin covering both knees was removed and each joint was mobilized by cutting the femur and the tibia. The knee joint was then opened and the yarn specimen was identified and excised together with surrounding tissue. Each specimen was then fixed in $12 \%$ buffered formalin for at least 48 hours and processed for light microscopy. After embedding in paraffin, $5 \mu \mathrm{m}$ thick sections were cut and stained with hematoxylinphloxin-safranin and Masson's trichrome.

The histopathologic response of the SFE and control yarns inserted in the knee joint for periods of 3, 10, and 30 days was evaluated using the following criteria: the phase and intensity of inflammation were respectively determined by the type

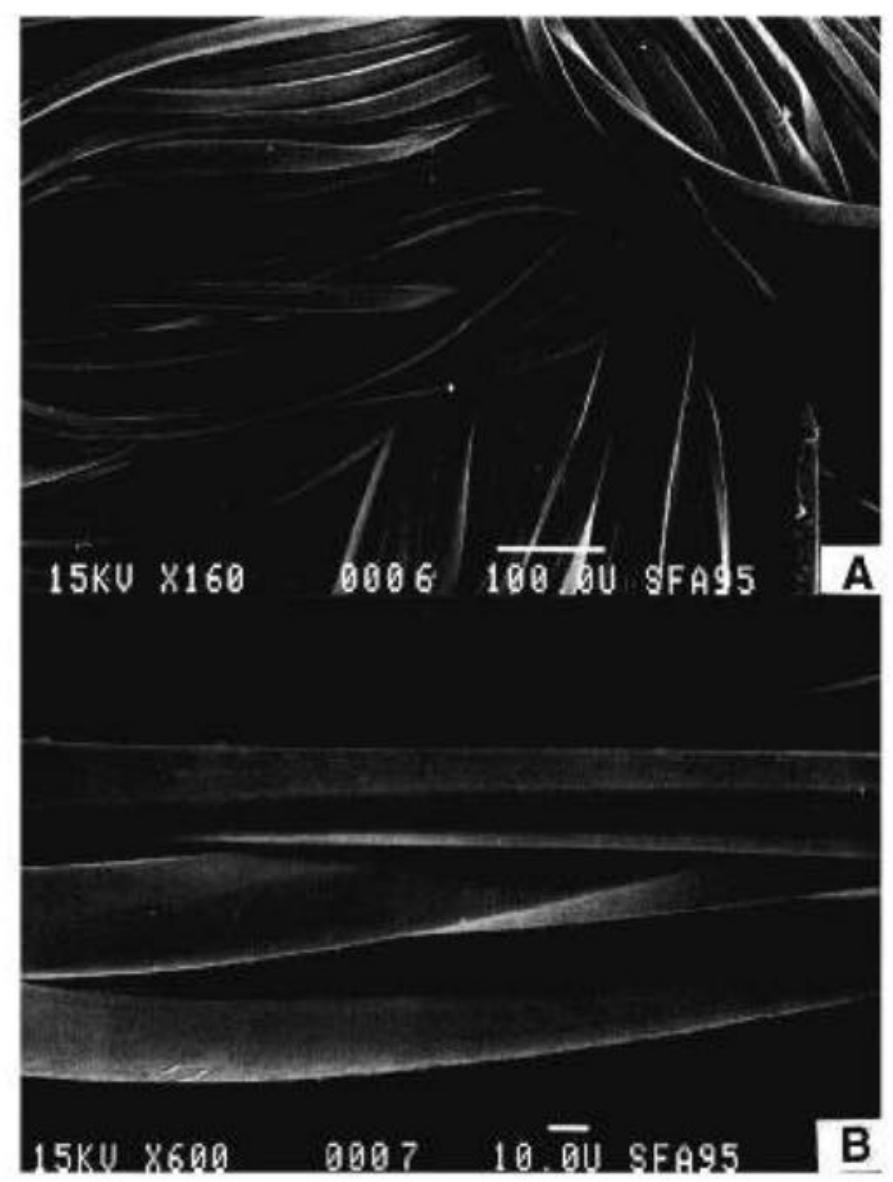

Figure 2. Scanning electron photomicrographs of the back of the supercritical fluid extraction cleaned fabric showing the absence of visible contaminants adhering to the surface of the filaments (original magnifications, A: $\times 160$, B: $\times 600$ ). 


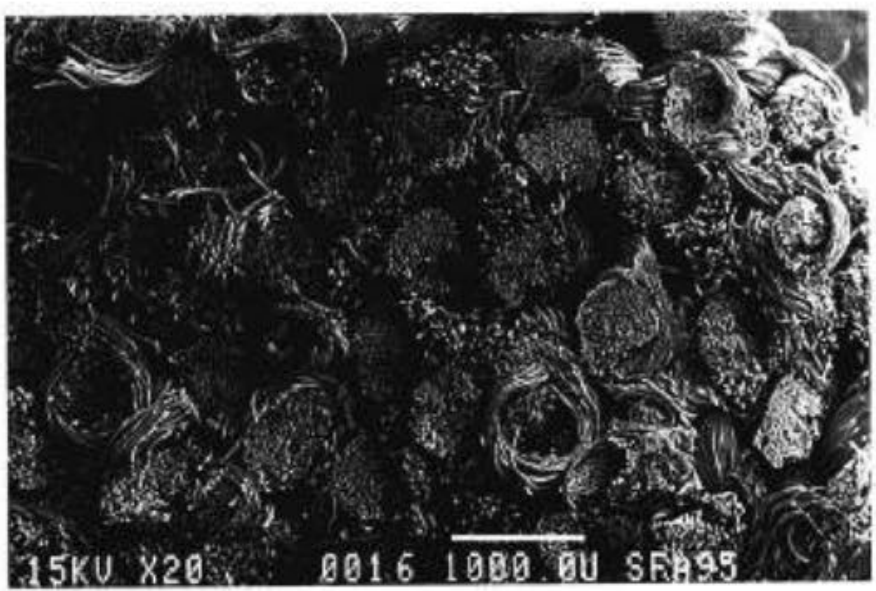

Figure 3. Scanning electron photomicrograph of a radial crosssectional cut through the central reinforced region of a supercritical fluid extraction cleaned prosthesis showing the coiled warp-knitted structure made from texturized polyester yarns reinforced by coarser, flat (nontexturized) weft insertion yarns. The outer edge seam is located at the 11 o'clock position (original magnification $\times 20$ ).

and number of inflammatory cells observed at the implant site. The presence of PMNs and lymphocytes provided evidence of the acute phase, whereas macrophages, foreign body giant cells (FBGCs), and collagen development with penetration in between the fibers indicated progression into the chronic phase. The severity of the reaction was considered "intense" if all the tissue surrounding the yarn specimen was highly infiltrated with inflammatory cells. It was deemed "moderate" if the cells were observed only in the tissue close to the specimen, and "mild" if the cells were located only between the fibers within the specimen itself. ${ }^{29}$ The current study was also undertaken to determine the type and severity of the inflammatory reaction generated by the synovial tissue and the synovial cell lining, as well as to evaluate the state of neovascularization within the two types of yarn specimens and their tissues.

\section{Results}

\section{Physical Characterization}

Surface Morphology. Scanning electron photomicrographs of the face and back of the control polyester fabric revealed evidence of surface contamination on the multifilament yarns (Figure 1). In contrast, the SFE treated fabric demonstrated that virtually all visible contaminants were removed by the SFE cleaning technique (Figure 2).

Physical Properties of Anterior Cruciate Ligament Prostheses. To fabricate the ACL prosthesis from the warp-knitted polyester fabric, a $7 \mathrm{~cm}$ length of the fabric was rolled tightly into a multilayered tubular structure and secured by sewing a longitudinal seam using a Class 501 single thread overedge stitch with a polyester sewing thread and 6.2 stitches per $\mathrm{cm}$. The coiled multilayer structure is most easily visualized from the cross-sectional view of the device cut in the radial direction (Figure 3).

The mean physical properties of the SFE cleaned and the control devices are listed in Table 1 . They indicate that the cleaning treatment results in a small amount of shrinkage in the
Table 1. Physical Properties of ACL Prostheses

\begin{tabular}{llcr}
\hline \multicolumn{1}{c}{ Property } & Units & SFE Cleaned & Control \\
\hline Thickness of prosthesis & & & \\
$\quad$ Major axis (2R) & $\mathrm{mm}$ & $7.3 \pm 0.2$ & $7.2 \pm 0.3$ \\
$\quad$ Minor axis $(2 \mathrm{r})$ & $\mathrm{mm}$ & $5.4 \pm 0.2$ & $5.4 \pm 0.2$ \\
Cross-sectional area $(\pi \mathrm{Rr})$ & $\mathrm{mm}{ }^{2}$ & 30.8 & 30.4 \\
Mass per unit length $(\mathrm{m})$ & $\mathrm{g} / \mathrm{m}$ & 21.3 & 19.9 \\
& $\mathrm{t}$ & 21,300 & 19,900 \\
Density of prosthesis & $\mathrm{g} / \mathrm{cm}^{3}$ & 0.690 & 0.654 \\
Porosity of prosthesis & $\%$ & 50.0 & 52.6 \\
\hline
\end{tabular}

longitudinal direction (about $2 \%$ ), which produces a slightly thicker, denser, and more compact prosthesis with a higher mass per unit length (linear density) and lower porosity.

Textile Structure of Fabric. The constructional features of the two-bar, warp-knitted structure are presented in Figure 4 and Table 2. The two extremities of the ACL prosthesis contain only a 17 tex, 30 filament texturized yarn knitted into a porous two-bar tricot stitch with approximately 5 wales per centimeter and over 14 courses per centimeter (Figure 4A). In the central region, an additional, coarser, 228 tex, 384 filament, flat (nontexturized) reinforcing yarn has been inserted in the weft direc-

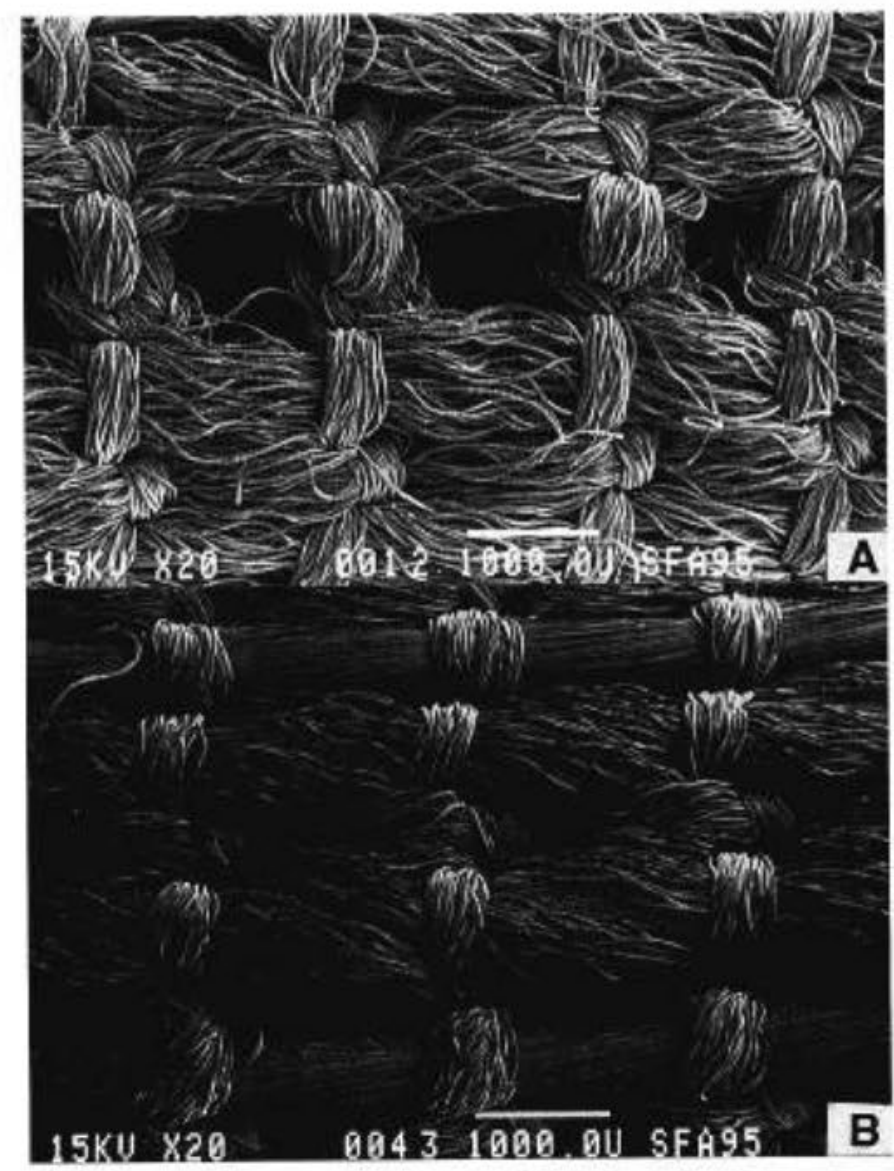

Figure 4. Scanning electron photomicrographs of the back of the two-bar, warp-knitted fabric. A: The extremities of the prosthesis are knitted entirely from texturized polyester yarns to give a porous structure. B: In the central region, additional coarser, flat (nontexturized) yarns have been inserted in the weft (horizontal) direction. 
Table 2. Textile Structure of Fabrics

\begin{tabular}{llcc}
\hline \multicolumn{1}{c}{ Property } & \multicolumn{1}{c}{ Units } & SFE Cleaned & Control \\
\hline Thickness of fabric $(\mathrm{hr})$ & $\mathrm{mm}$ & 0.493 & 0.452 \\
Mass per unit area (M) & $\mathrm{g} / \mathrm{m}^{2}$ & 348 & 317 \\
Density of fabric & $\mathrm{g} / \mathrm{cm}^{3}$ & 0.737 & 0.700 \\
Porosity of fabric & $\%$ & 48.9 & 49.3 \\
Knitted stitch count & wales/cm & $4.9 \pm 0.1$ & $4.8 \pm 0.0$ \\
& courses/cm & $14.6 \pm 0.2$ & $14.3 \pm 0.0$ \\
Stitch density & $\mathrm{cm}^{-2}$ & 71.5 & 68.6 \\
Weft insertion count & picks/cm & $8.3 \pm 0.3$ & $8.2 \pm 0.2$ \\
\hline
\end{tabular}

tion at a frequency of about 8 picks per centimeter, which reduces the porosity to a value of $48.9 \%$ (Table 2 and Figure 4B).

\section{Chemical Characterization}

Electron Spectroscopy for Chemical Analysis. The results of the survey scans confirm the presence of impurities on the surfaces of both samples (Table 3). Although the SFE treated prosthesis contained smaller quantities of silicon and phosphorus, it did contain some residual nitrogenous species that were not present on the scoured control. Such species may have been present on the original sample and completely removed by the scouring treatment. On the other hand, they may have been deposited during the SFE treatment because, for example, of impurities in the $\mathrm{CO}_{2}$.

Fourier Transform Infrared Spectroscopy. No major differences in infrared spectra were observed between the two types of polyester yarn used to construct the prosthesis (Figure 5). In other words, the texturized polyester yarn knitted throughout the length of the device (Figures $\mathbf{4 A}$ and $\mathbf{5 A}$ ) gave the same spectrum as the coarser, flat (nontexturized) reinforcing yarn, which was found only in the central region (Figures $4 \mathrm{~B}$ and 5B).

Differences in infrared spectra were evident, however, when the SFE cleaned yarns were compared with the scoured controls. Higher levels of absorption in the $\mathrm{C}-\mathrm{H}$ aliphatic stretching region (2800-3000 $\mathrm{cm}^{-1}$ ) were observed with scoured control yarns (Figure 5C and D). Again, because the spectra of the two SFE treated yarns were closer than the scoured controls to that of a pure PET standard (Figure 5E), it is likely that the control samples contained more surface contaminants. ${ }^{22-24}$

Differential Scanning Calorimetry. The DSC results demonstrated major differences in initial thermal properties and microcrystalline structure between the two types of polyester yarn, as well as changes resulting from the SFE treatment (Table 4). The texturized knitted control yarn had a premelt endotherm peak at $257.3^{\circ} \mathrm{C}$, and only a shoulder at the melting point, whereas the nontexturized reinforcing control yarn had a premelt shoulder followed by a melt peak at $262.6^{\circ} \mathrm{C}$ (Figure

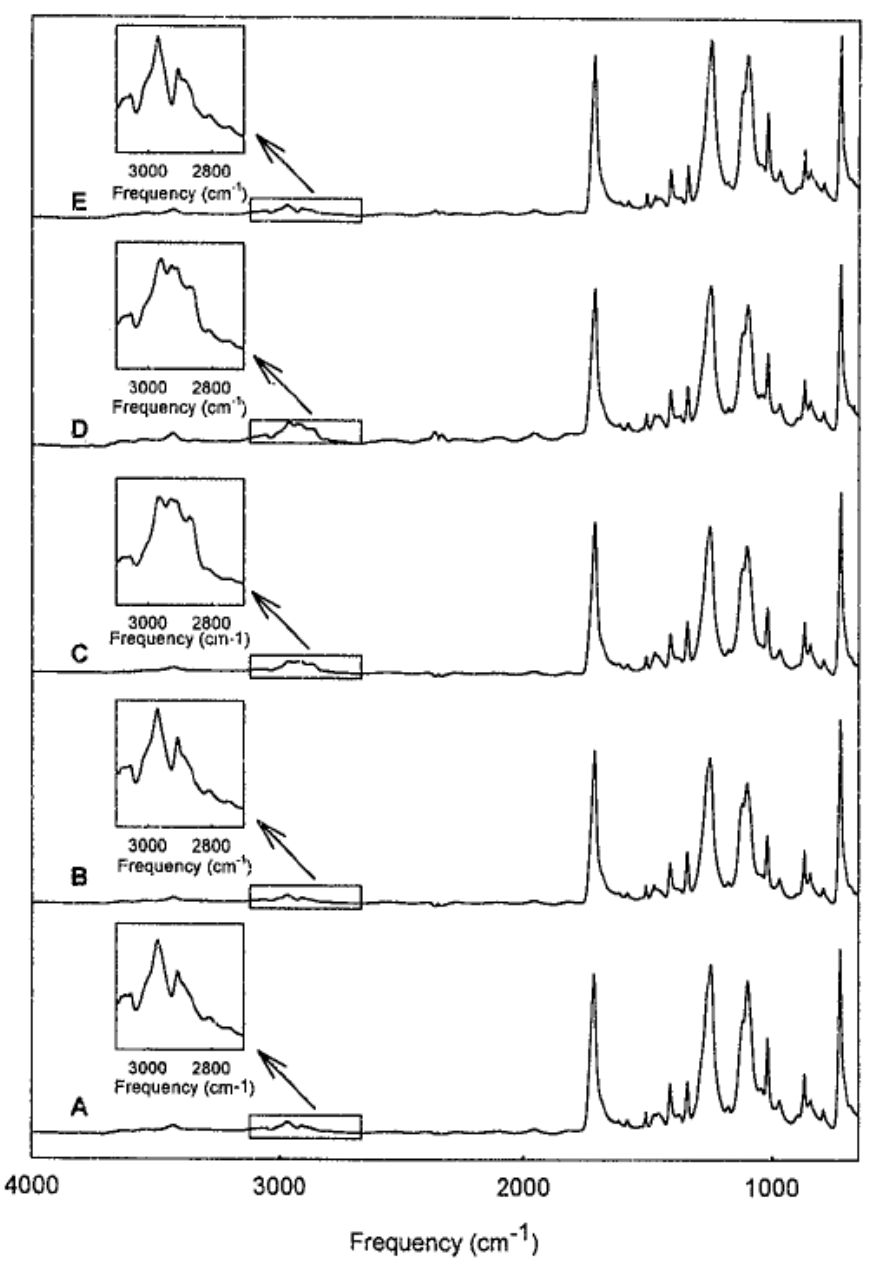

Figure 5. Fourier transform infrared spectra of the polyester yarns removed from the supercritical fluid extraction (SFE) treated and control prostheses: A: SFE treated texturized knitted yarn. B: SFE treated nontexturized reinforcing yarn. C: Control texturized knitted yarn. D: Control nontexturized reinforcing yarn. E: Poly(ethylene terephthalate) standard reference yarn.

6B and D). In addition to having a different shaped melt peak, the texturized knitted yarn had a higher heat of fusion and a corresponding larger crystallinity index, giving it similar thermal properties to those reported in the literature for texturized PET yarn supplied by Rhône-Poulenc Fibres SA (Lyon, France). ${ }^{22}$

Although the relative size of the premelt and melt endotherms of the two SFE treated yarns were similar to their respective controls (Figure 6), their heats of fusion appeared to change after SFE processing: the one for the texturized knitted yarn fell, whereas the one for the reinforcing yarn increased (Table 4).

Level of Extractables. The gravimetric results after multiple

Table 3. ESCA Survey Scans Showing Percentage Composition of SFE Cleaned and Control ACL Prostheses

\begin{tabular}{|c|c|c|c|c|c|c|c|c|c|c|}
\hline Prosthesis & $\mathrm{C}$ & $\mathrm{O}$ & $\mathrm{N}$ & $\mathrm{Si}$ & $\mathrm{Cl}$ & $\mathrm{Ca}$ & $\mathrm{Mg}$ & $\mathrm{Na}$ & $\mathrm{s}$ & $\mathrm{P}$ \\
\hline $\begin{array}{l}\text { SFE cleaned } \\
\text { Control }\end{array}$ & $\begin{array}{l}74.1 \\
73.0\end{array}$ & 21.1 & 1.4 & 1.4 & 0.1 & 0.7 & 0.5 & 0.6 & - & 0.2 \\
\hline & & 22.1 & - & 2.2 & - & 0.6 & 0.2 & 0.6 & 0.3 & 1.0 \\
\hline
\end{tabular}


Table 4. Differential Scanning Calorimetry Results for Yarns Removed From SFE Cleaned and Control Prostheses

\begin{tabular}{lcccc}
\hline Yarn Sample & $\begin{array}{c}\mathrm{Tpm} \\
\left({ }^{\circ} \mathrm{C}\right)\end{array}$ & $\begin{array}{c}\mathrm{Tm} \\
\left({ }^{\circ} \mathrm{C}\right)\end{array}$ & $\begin{array}{c}\Delta \mathrm{H} \\
(\mathrm{J} / \mathrm{g})\end{array}$ & $\begin{array}{c}\text { Crystallinity } \\
\text { Index }\end{array}$ \\
\hline $\begin{array}{l}\text { SFE texturized knitted } \\
\quad \text { yarn }\end{array}$ & 258.2 & - & 50.7 & 0.36 \\
$\begin{array}{l}\text { Control texturized knitted } \\
\text { yarn }\end{array}$ & 257.3 & - & 58.6 & 0.42 \\
$\begin{array}{l}\text { SFE nontexturized } \\
\text { reinforcing yarn }\end{array}$ & - & 263.3 & 55.3 & 0.40 \\
$\begin{array}{c}\text { Control nontexturized } \\
\text { reinforcing yarn }\end{array}$ & - & 262.6 & 52.2 & 0.37 \\
\hline
\end{tabular}

Tpm, pre-melting temperature; Tm, melting temperature; $\Delta \mathrm{H}$, heat of fusion.

solvent extractions indicated that the SFE cleaned device had a lower level of total extractables on its surface than the control prosthesis (Table 5). This was most evident after the first two extractions in the least polar solvents, hexane and 1,1,1-trichloroethane, which are known to remove oils, waxes, silicones, oligomers, acrylics, polyurethanes, and polyvinyl acetate. ${ }^{27}$ A total of $0.70 \%$ of extractables was removed, compared to $0.10 \%$ for the SFE cleaned sample. The residual total level of extractables of $0.27 \%$ for an SFE cleaned sample lies at the bottom of the range of $0.25-1.93 \%$ reported for other commercial implantable devices such as vascular prostheses. ${ }^{4,5,22}$

\section{Biologic Characterization}

In Vitro Cell Activation Study. The cytofluorometric measurements of CD18 integrin expression on activated human PMNs after incubation with the SFE cleaned and control polyester fabrics are shown in Figure 7 . The results demonstrate that the control fabric induced a significantly higher CD18 expression than that of the SFE treated fabric. The mean \pm standard deviation for the fluorescence peak shift observed for the control fabric was $88.2 \pm 64.9$, which was in a similar range to the value obtained with the positive control, tumor necrosis factor $(58.5 \pm 71.5)$. A lower level of expression was observed for the SFE treated fabric, which had a mean fluorescence shift of only $10.5 \pm 21.0$, whereas those observed for the Tygon O-rings and the two negative reference materials, LDPE and PDMS, were zero.

In Vivo Implantation Study. Histologic examination of the SFE treated polyester yarns implanted without fixation in the intra-articular knee joint of rats revealed that, after only 3 days, the yarns were surrounded by a fibrin network entrapping polymorphonuclear cells, plasmocytes, and erythrocytes. The inflammatory response was mild and in an acute phase. At 10 days, this reaction had moved to a chronic phase of inflammation, as revealed by the presence of macrophages, FBGCs, and a few PMNs. Tissue development around the yarns was thin and not well infiltrated between the individual filaments, although fibrin was still present in significant amounts in the yarn bundle. A similar histologic picture was observed after 30 days. The inflammatory response was still moderate and chronic, with the presence of macrophages, FBGCs, and some eosinophils being located close to the polyester yarn. There was only a thin layer of tissue encapsulation with little neocol- lagen synthesis surrounding the implant, and the synovial membrane was mildly hyperplastic, pointing to the low reactivity level of the SFE cleaned device (Figure 8).

The control polyester yarns explanted after 3 days revealed an acute inflammatory response similar to that of the SFE treated prosthesis, except that it was moderate in intensity and the yarns were surrounded by a fibrin network entrapping red blood cells, plasmocytes, and PMNs that were predominantly eosinophils. After 10 days, however, the cellular response moved to a transitional phase, with the appearance of macrophages and FBGCs in contact with the individual polyester filaments. Traces of fibrin and a few PMNs were still present near the implant. The healing response was also characterized by the development of a thick tissue reaction all around the control polyester yarns. It was highly cellular and showed evidence of fibroblastic proliferation and neocollagen synthesis (Figure 9); it also contained a number of neovessels. After 30 days in vivo, the control yarns provoked a histologic reaction similar to that observed at 10 days, except that now the inflammatory response had reached its chronic phase. A summary of these observations is found in Table 6 .

\section{Discussion}

The focus of the study was to assess the impact of SFE cleaning on the physical, chemical, and biologic characteristics of

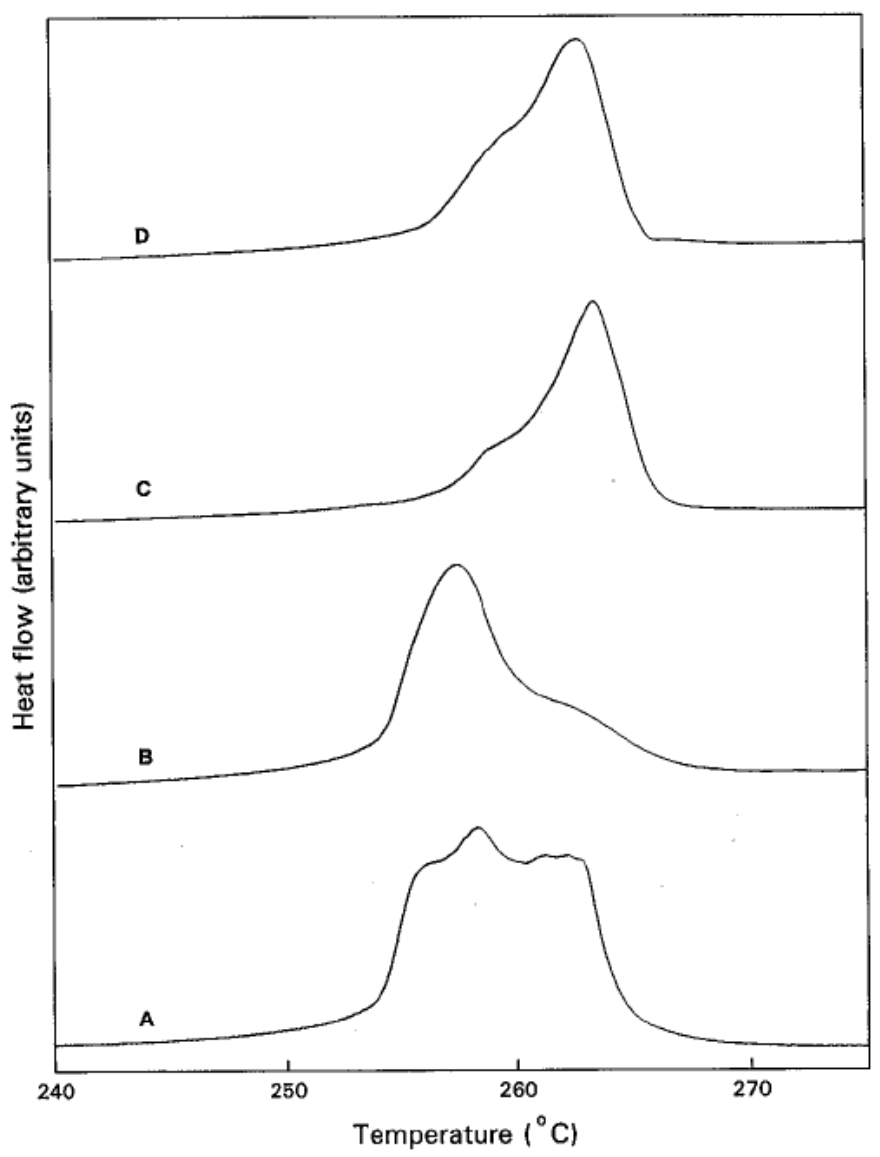

Figure 6. Differential scanning calorimetry thermograms of polyester yarns removed from the supercritical fluid extraction (SFE) treated and control prostheses. A: SFE treated texturized knitted yarn. B: Control texturized knitted yarn. C: SFE treated nontexturized reinforcing yarn. D: Control nontexturized reinforcing yarn. 
Table 5. Level of Extractables From ACL Prostheses (\%)

\begin{tabular}{|c|c|c|c|c|c|c|}
\hline Prosthesis & Hexane & $\begin{array}{c}1,1,1 \\
\text { Trichloroethane }\end{array}$ & Methanol & Water & $\begin{array}{l}0.1 \mathrm{~N} \\
\mathrm{HCl}\end{array}$ & Total \\
\hline $\begin{array}{l}\text { SFE cleaned } \\
\text { Control }\end{array}$ & $\begin{array}{l}0.10 \\
0.64\end{array}$ & $\begin{array}{l}0.00 \\
0.06\end{array}$ & $\begin{array}{l}0.06 \\
0.11\end{array}$ & $\begin{array}{l}0.00 \\
0.00\end{array}$ & 0.11 & 0.27 \\
\hline
\end{tabular}

the knitted polyester ACL prosthesis. The following three sections review the three effects before presenting the apparent advantages and limitations of using the SFE process as a routine cleaning method in the biomedical device industry.

\section{Effect on Physical and Dimensional Properties}

The effect of SFE treatment on the physical and dimensional properties of the $\mathrm{ACL}$ device and the textile fabric can be seen from the results presented in Tables 1 and 2. As indicated previously, the length of the prosthesis shrank by about $2 \%$, as measured in terms of mass per unit length (Table 1), which corresponded to a $2 \%$ increase in wale count measured on the unrolled and flattened fabric (Table 2). In addition, the fabric was found to shrink by about the same margin in the warp direction (course count), which explains the observed increase of about $4 \%$ in stitch density (areal shrinkage; Table 2) as well as the decrease of about $5 \%$ in the porosity of the prosthesis (Table 1).

Such shrinkage or contraction is to be expected when highly oriented, semicrystalline polymers, such as PET filament yarns, are exposed to elevated temperatures and pressures. ${ }^{25,30,31}$ What is yet to be determined is whether this shrinkage phenomenon has any effect on the mechanical, tensile, and fatigue properties of the ACL prosthesis.

\section{Effect on Chemical Properties}

With respect to surface chemistry, the empiric findings from the ESCA, Fourier transform infrared spectroscopy, and extraction experiments in this study have demonstrated that the SFE process was effective in removing most of the contaminants and impurities on or near the surface of the ACL prosthesis. Although the exact nature of these impurities is not known,

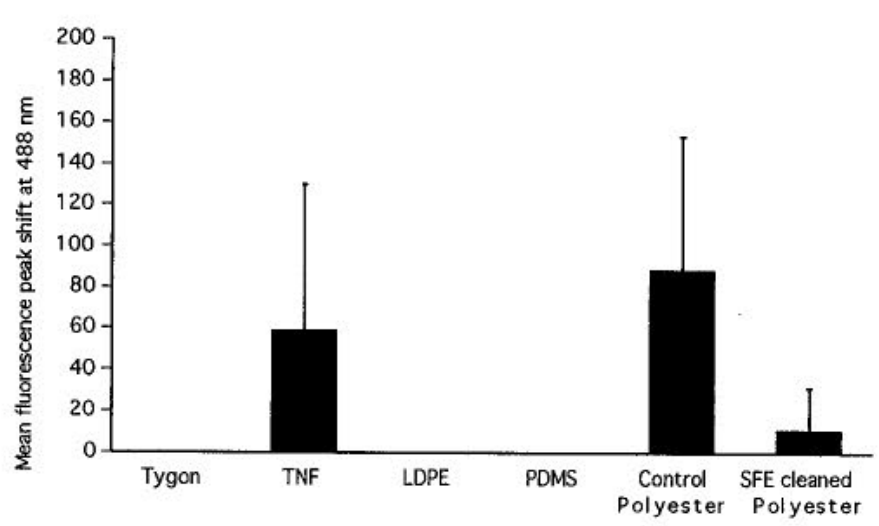

Figure 7. CD18 integrin expression on activated human polymorphonuclear cells after incubation with supercritical fluid extraction cleaned and control polyester fabrics, as well as with positive and negative control materials. the results obtained to date point to the removal of oils, waxes, or oligomers containing oxidized hydrocarbons, silicones, and phosphorus compounds.

In addition to changing the surface chemistry, the SFE treatment modified the microcrystalline structure of the PET yarns, but the effect was not the same for the two types of yarn, in part because they had two different prior thermal histories and were exposed to different types and levels of stress within the knitted fabric during the SFE process.

In particular, the weft-inserted, nontexturized reinforcing yarn was held under longitudinal tension in the warp-knitted structure (Figure $\mathbf{4 B}$ ). The elevated temperature and pressure
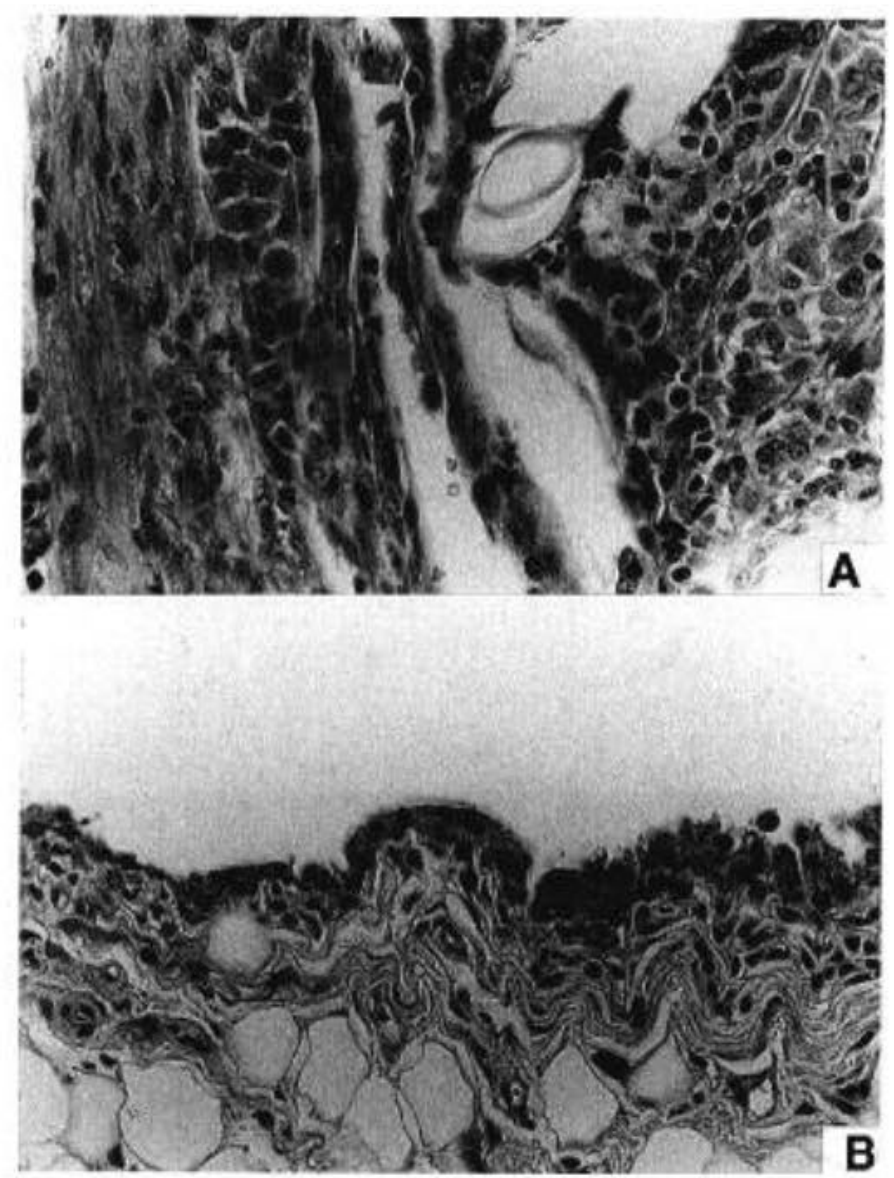

Figure 8. Light photomicrographs of the tissue reaction surrounding supercritical fluid extraction (SFE) treated polyester yarns after implantation in the knee joint of rats. A: As early as 10 days after implantation, the inflammatory response was mild and in a chronic phase with few macrophages and foreign body giant cells (FBGCs) (original magnification $\times 500$ ). B: A localized mild hyperplasia of the synovial cell lining was also observed at 10 days in the region close to the SFE polyester fibers (original magnification $\times 500)$. 


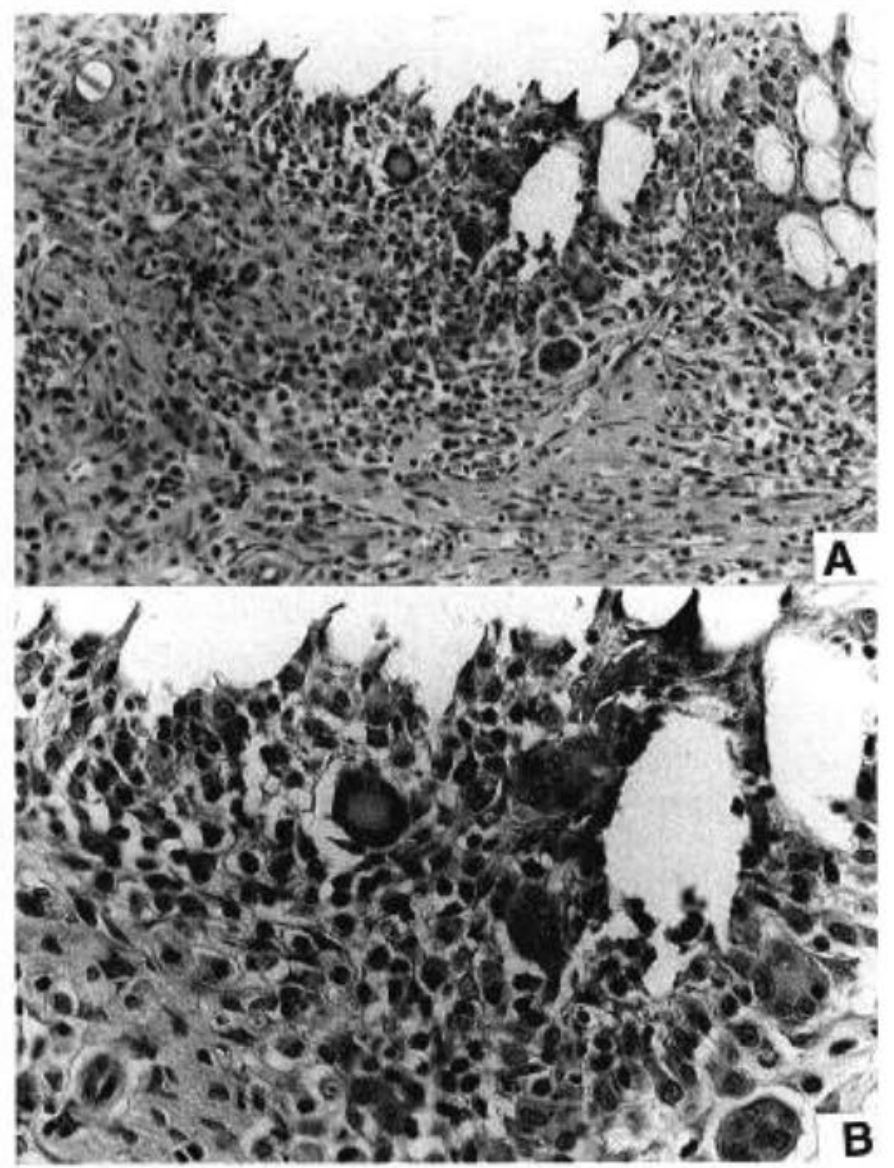

Figure 9. Light photomicrographs of the tissue reaction surrounding control polyester yarns after implantation in the knee joint of rats. After 10 days, the inflammatory reaction was characterized by thick collagenous tissue development infiltrated by numerous inflammatory cells, including polymorphonuclear cells, plasmocytes, macrophages, and foreign body giant cells (original magnifications, A: $\times 250, B: \times 500$ ).

conditions of the SFE process therefore caused this yarn to be annealed at a fixed length. Such annealing conditions encourage the coalescence of smaller crystallites, the formation of larger crystalline regions, and an overall increase in the level of crystallinity. ${ }^{25,30}$ Such changes corresponded to the observed changes in DSC thermograms in which the effect of SFE processing was to reduce the size of the premelt endotherm shoulder while increasing the overall area under the melt and premelt peak $(\Delta H)$ (Figure 6C and D).

On the other hand, the texturized knitted yarns were in a relaxed state in the warp-knitted fabric (Figure 4A), and consequently they tended to shrink or contract in the longitudinal direction when exposed to the elevated temperatures of the SFE process. Annealing under such conditions would also have reduced the number of smaller crystalline regions, but because of an absence of longitudinal stresses to encourage preferential molecular orientation or alignment, there would have been no growth in the number and size of larger crystallites. ${ }^{31}$ This is in agreement with the DSC results that showed a significant drop in the height of the premelt peak, as well as a fall from 0.42 to 0.36 in the overall crystallinity index (Figure 6A and B and Table 4). It is not known whether these changes in microcrystalline structure will improve or compromise the long-term mechanical, tensile, and fatigue properties of the $\mathrm{ACL}$ device, or influence its long-term biostability in vivo.

\section{Effect on Biologic Properties}

The results from the PMN activation experiment confirmed a very high level of CD18 integrin expression for the control material. In fact, the value of $88.2 \pm 64.9$ was at least as high as the value of $58.5 \pm 71.5$ for the positive control. The effect of the SFE treatment was to reduce this very high level to a value of $10.5 \pm 21.0$, which, although higher than the negative controls, falls neatly within the range of 7.5-10.6 obtained previously with typical commercial polyester devices. ${ }^{2}$

In view of the fact that this cell activation assay has been found to be a good predictor of the in vivo healing behavior of various polyester vascular grafts, we can conclude that the use of the SFE cleaning treatment to remove surface contaminants from the $\mathrm{ACL}$ devices improved the biocompatibility and promoted a satisfactory cellular response in vivo. ${ }^{2}$

These findings are supported by the histologic evidence from the 30 day animal trial, in which the cellular response was both milder and the rate of healing was more rapid after the SFE treatment had removed most of the surface contaminants. Other histologic investigations have also found that clean polyester ACL prostheses are well tolerated in animals in terms of their inflammatory and immunologic responses. ${ }^{32-34}$ In addition, this study has shown that in the rat there is less of a tendency toward synovial hyperplasia with the SFE cleaned device. However, proof of its long-term biofunctionality will not be demonstrated until in vivo studies have been completed in which the prosthesis is evaluated for mechanical, fatigue, and tribologic performance when implanted under tension in the articulating knee joint. ${ }^{35,36}$

Table 6. Summary of the Histologic Observations of the SFE and Control Polyester Yarns Implanted in the Knee Joint of Rats for Periods of 3,10 , and 30 days

\begin{tabular}{lclllll}
\hline Materials & $\begin{array}{c}\text { Implantation } \\
\text { Times }(\mathrm{d})\end{array}$ & Inflammatory Response & Tissue Reaction & $\begin{array}{c}\text { Collagen } \\
\text { Synthesis }\end{array}$ & Neovessels & $\begin{array}{c}\text { Synovial } \\
\text { Hyperplasia }\end{array}$ \\
\hline SFE cleaned & 3 & Mild: acute phase & None & None & None & None \\
& 10 & Moderate: chronic phase & Thin mildly cellular & Little & Several & Mild \\
& 30 & Moderate: chronic phase & Thin: less cellular & Little & Few & Mild \\
Control & 3 & Moderate: acute phase & None & None & None & Mild \\
& 10 & Moderate: transition phase & Thick: highly cellular & Abundant & Several & Moderate \\
& 30 & Moderate chronic phase & Thick: less cellular & Abundant & Several & Mild \\
\hline
\end{tabular}




\section{Advantages of Supercritical Fluid Extraction}

Supercritical fluid extraction, using $\mathrm{CO}_{2}$ as the mobile phase, has already been shown to be an efficient method for the removal and identification of "extractables" or "leachables," such as oligomers and polymer additives, from synthetic biomaterials, and the technique has been recommended as a standard method for biocompatibility testing. ${ }^{11,12}$ The process has a number of advantages over traditional liquid extraction methods that use a series of different solvents. ${ }^{27}$ It is relatively simple, rapid, and inexpensive to perform, particularly in the recovery of the "extractables." This is because there are no losses associated with concentrating the extract, and there are no. environmental risks due to solvent emission and waste disposal. Carbon dioxide reaches the supercritical fluid state at comparatively low temperatures and pressures (7.38 MPa and $31^{\circ} \mathrm{C}$ ). It is relatively cheap to purify and recycle, it has a low viscosity, it is nontoxic, nonflammable, and noncorrosive, and it is a safe and natural product that leaves no trace impurities once the biomaterial is returned to ambient conditions. ${ }^{12}$

\section{Limitations of Supercritical Fluid Extraction}

The solvating power or diffusivity of supercritical $\mathrm{CO}_{2}$ depends on its density, which increases with pressure and decreases with temperature. Hence, by changing the temperature and pressure conditions, the solvating power of $\mathrm{CO}_{2}$ can be modified to make the extraction process more efficient for a particular product and process. If, however, the conditions cause the PET polymer to experience undesirable changes, such as annealing, contraction, and reorganization of its microcrystalline structure, ${ }^{30,31}$ as observed through the DSC analysis in this study, then a systematic approach is required to optimize the temperature and pressure conditions. Although this annealing process clearly had no negative impact on the shortterm biocompatibility of the $\mathrm{ACL}$ prostheses, it is not known whether it had a positive or negative effect on the device's long-term biostability. Nevertheless, these measurable microstructural changes will be of assistance in defining the limits of the processing conditions for SFE treatment of polyester textiles.

A second limitation concerns the fact that supercritical fluid $\mathrm{CO}_{2}$ is known to be a strong solvent for nonpolar compounds, such as hydrocarbons, oils, and lipids, but is less effective with polar molecules, such as amino acids and proteins. ${ }^{12-14}$ This limitation has been well demonstrated by the findings of this study in view of the fact that over $85 \%$ of the nonpolar contaminants (e.g., waxes, oils, silicones, oligomer, acrylics, polyurethanes, and vinyl acetate) found on the control sample and extracted with hexane and 1,1,1,-trichloroethane, had been removed by the SFE treatment (Table 5). However, the ESCA and extraction analysis results confirmed that some residual impurities, containing nitrogen, calcium, magnesium, and sodium ions, which were polar species soluble in $0.1 \mathrm{~N}$ hydrochloric acid, were still present on the surface of the SFE cleaned device. Although the total amount of these impurities is low and compares favorably with levels for "residuals" measured on other commercial implantable devices, $4,5,22$ nevertheless, the origin of such contaminants needs to be identified.

In view of these encouraging results, further research is being conducted, particularly in terms of expanding the matrix of effective SFE conditions and assessing the effect of adjusting the polarity of the fluid through the addition of polar entrainers such as methanol. This may facilitate greater extraction of polar surface contaminants. In addition, work is continuing to identify the type and origin of residual contaminants and to correlate the structural changes due to the SFE process with the devices' long-term in vivo performance.

\section{Conclusion}

The use of a $\mathrm{CO}_{2}$ SFE process has been successful in removing most of the surface contaminants and bringing the residual amount of extractables to an acceptably low level in the manufacture of a polyester ACL prosthesis. In addition to being effective in removing nonpolar impurities and thereby contributing to a more biocompatible device that heals more rapidly when implanted in the knee joint of rats, the SFE process caused some contraction of the polyester yarn, shrinkage of the textile fabric, and changes in the polymer's microcrystalline structure. Small, residual levels of nitrogen containing compounds, polar compounds, and anionic salts were still present as surface contaminants after SFE treatment.

\section{Acknowledgment}

Supported by the Quebec Biomaterials Institute and Bioland-Biomatériaux.

The authors thank Suzanne Bourassa, Claire Letendre, Deborah Hodgson, and Jean-François Pageau for their technical assistance.

\section{References}

1. Marchand RE, Miller KM, Anderson JM: In vivo biocompatibility studies: $\mathrm{V}$. in vivo leukocyte interactions with Biomer. J Biomed Mater Res 18: 1169-1190, 1984.

2. Marois Y, Guidoin R, Roy R, et al: Selecting valid in vitro biocompatibility tests that predict the in vivo healing response of synthetic vascular prostheses. Biomaterials 17: 1835-1842, 1996.

3. King $M$, Blais $P$, Guidoin R, et al: Polyethylene terephthalate (Dacron) vascular prostheses: material and fabric construction aspects, in Williams DF (ed), Biocompatibility of Clinical Implant Materials, Vol 2, Boca Raton, FL, CRC Press, 1981, pp. 177207.

4. Guidoin $R$, King $M$, Therrien $M$, et al: The Atrium Plasma TFE arterial prosthesis: physical and chemical characterization. In Szycher M (ed), High Performance Biomaterials, Lancaster, PA, Technomic, 1991, pp. 381-399.

5. Torché D, Guidoin R, Boyer D, et al: An arterial prosthesis from Argentina: the Barone Microvelour arterial graft. J Biomater App/ 3: 427-453, 1989.

6. McHugh M, Krukonis VJ: Supercritical Fluid Extraction: Principles and Practice, Boston, Butterworth, 1986.

7. Hannay JB, Hogarth J: On the solubility of solids in gases. Proceedings of the Royal Society (London) 29: 324-326, 1879.

8. Zosel K: Process for decaffeination of coffee. U.S. Patent 4,260,639, 1974.

9. De Filippi RP: Carbon dioxide as a solvent: application to fats, oils and other materials. Chemistry and Industry June 12, 1982, pp. 390-394.

10. Bamberger T, Erickson JC, Cooney CL: Measurement and model prediction of solubilities of pure fatty acids, pure triglycerides and mixtures of triglycerides in supercritical carbon dioxide. Journal of Chemical Engineering and Data 33: 327-333, 1988.

11. Küppers ST: The use of temperature variation in supercritical fluid extraction of polymers for the selective extraction of low molecular weight components from poly(ethylene terephthalate). Chromatograph 33: 434-440, 1992.

12. Braybrook JH, Mackay GA: SFE of polymer additives for use in 
biocompatibility testing. Polymer International 27: 157-164, 1992.

13. Fages J, Marty A, Delga C, Condoret JS, Combes D, Frayssinet P: Use of supercritical $\mathrm{CO}_{2}$ for bone delipidation. Biomaterials 15: 650-656, 1994

14. Frayssinet $P$, Asimus $E$, Autefage A, Fages J: Histological evaluation of xenogeneic bone treated by supercritical carbon dioxide implanted into sheep. Journal of Materials Science: Materials in Medicine 6: 473-478, 1995.

15. Koros WJ, Paul DR, Fujii M, Hopfenberg HB, Stannett V: Effect of pressure on carbon dioxide transport in poly(ethylene terephthalate). Journal of Applied Polymer Science 21: 2899-2904, 1977.

16. Koros WJ, Paul DR: Transient and steady-state permeation in poly(ethylene terephthalate) above and below the glass transition. Journal of Polymer Science: Polymer Physics Edition 16: 2171 $2187,1978$.

17. Standard Method for Measuring Thickness of Textile Materials, ANSI/ASTM D 1777-64. Annual Book of Standards, Vol 07.01, Philadelphia, American Society for Testing and Materials, 1993.

18. Standard Practice for Use of the Tex System to Designate Linear Density of Fibers, Yarn Intermediates and Yarns, ASTM D 861 89. Annual Book of Standards, Vol 07.01, Philadelphia, American Society for Testing and Materials, 1993.

19. Guidoin R, King MW, Marceau D, et al: Textile arterial prostheses: is water permeability equivalent to porosity? J Biomed Mater Res 21: 65-87, 1987.

20. Mendes-Soares B, King MW, Marois Y, et al: In vitro characterization of a fluoropassivated gelatin impregnated polyester mesh for hernia repair. J Biomed Mater Res 32: 259-270, 1996.

21. Standard Tolerances for Knitted Fabrics, ASTM D 3887-94. Annual Book of Standards, Vol 07.02, Philadelphia, American Society for Testing and Materials, 1994.

22. King MW, Marois $Y$, Guidoin R, et al: Evaluating the Dialine vascular prosthesis knitted from an alternative source of polyester yarns. J Biomed Mater Res 29: 595-610, 1995.

23. Paynter RW, King MW, Guidoin RG, Rao T: The surface composition of commercial polyester arterial prostheses: an XPS study. Int J Artif Organs 21: 189-194, 1989.

24. Koenig JL: Modern data processing techniques for Fourier transform infrared spectroscopy, in Dung JR (ed), Analytical Applica- tions of FTIR to Molecular and Biological Systems, D. Reidel Publishing Company, Hingham, MA, 1980, pp. 79-86.

25. Elenga R, Seguela R, Rietsch F: Thermal and mechanical behaviour of crystalline poly(ethylene terephthalate): effects of high temperature annealing and tensile drawing. Polymer 32:1975$1982,1991$.

26. Mehta $A$, Gaur $U$, Wunderlich B: Equilibrium melting parameters of poly(ethylene terephthalate). Journal of Polymer Science: Polymer Physics Edition 15: 289-296, 1978.

27. Finishes in Textiles: Identification. ANSI/AATCC Test Method 941992. Technical Manual, Vol 69, Research Triangle Park, NC, American Association of Textile Chemists and Colorists, 1994.

28. Jakubiec B, Roy R, Belles-Isles M, Marois Y, Guidoin R: Measurement of CD11/CD18 integrin expression on the polymorphonuclear cell surface after incubation with synthetic vascular prostheses. ASAIO J 40: M616-M618, 1994.

29. Marois $Y$, Cronier B, Guidoin R, et al: Synovial healing response to synthetic ligamentous fibres implanted in the knee joint of the rat, in Mainard D, Delagoutte JP (eds), Actualités en Biomatériaux, Vol 3, Paris, Romillat, 1996, pp. 339-348.

30. Wilson MPW: Shrinkage and chain folding in drawn poly(ethylene terephthalate) fibers. Polymer 15: 277-282, 1974.

31. Prevorsek EA, Tirpak GA, Harget PJ, Reimschuessel AC: Effects of thermal contraction on structure and properties of polyethylene terephthalate fibers. Journal of Macromolecular Science: Part B, Physics 9: 733-759, 1974.

32. Marois $Y$, Roy R, Vidovszky T, et al: Histopathological and immunological investigations of synthetic fibres and structures used in three prosthetic anterior cruciate ligaments: in vivo study in the rat. Biomaterials 14: 255-262, 1993.

33. Arnoczky SP, Warren RF, Minei JP: Replacement of the anterior cruciate ligament using a synthetic prosthesis. An evaluation of graft biology in the dog. Am J Sports Med 14: 1-6, 1986.

34. Thomas NP, Turner IG, jones CB: Prosthetic anterior cruciate ligaments in the rabbit: a comparison of 4 types of replacement. J Bone Joint Surg Br 69: 312-316, 1987.

35. Park JP, Grana WA, Chitwood JS: A high strength Dacron augmentation for cruciate ligament reconstruction: a two-year study. Clin Orthop 196: 175-185, 1985.

36. Amis AA, Camburn M, Kempson SA, Radford WJP, Stead AC: Anterior cruciate ligament replacement with polyester fibre: a long-term study of tissue reactions and joint stability in sheep. J Bone Joint Surg Br 74: 605-613, 1992. 